\title{
In Silico Fight Against Novel Coronavirus by Finding Chromone Derivatives as Inhibitor of Coronavirus Main Proteases Enzyme
}

Nayim Sepay ( $\square$ nayimsepay@yahoo.com )

Jadavpur University https://orcid.org/0000-0001-7702-3989

Nadir Sepay

Plant Biotechnology Laboratory, Post Graduate Department of Botany, Ramakrishna Mission

Vivekananda Centenary College, Rahara, Kolkata -700118, India.

Ashique Al Hoque

Jadavpur University

Rina Mondal

Department of Chemistry, Uluberia College, Howrah, West Bengal 711 315, India.

Umesh Chandra Halder

Jadavpur University

Mohd. Muddassir

King Saud University

\section{Research Article}

Keywords: Novel Coronavirus, mutant CoV Mpro, benzylidenechromanones, ADME, DFT, Docking

Posted Date: March 13th, 2020

DOI: https://doi.org/10.21203/rs.3.rs-17437/v1

License: (c) (1) This work is licensed under a Creative Commons Attribution 4.0 International License.

Read Full License

Version of Record: A version of this preprint was published at Structural Chemistry on May 13th, 2020. See the published version at https://doi.org/10.1007/s11224-020-01537-5. 


\section{Abstract}

Novel coronavirus, 2019-nCoV is a danger to the world and is spreading rapidly. Very little structural information about 2019-nCoV make this situation more difficult for drug designing.

Benzylidenechromanones, naturally occurring oxygen heterocyclic compounds, having capability to inhibit various protein and receptors, have been designed here to block mutant variety of coronavirus main protease enzyme (CoV M ${ }^{\text {pro }}$ ) isolated from 2019-nCoV with the assistance of molecular docking, bioinformatics and DFT. ( Z )-3-(4'-chlorobenzylidene)-thiochroman-4-one showed highest binding affinity to the protein. Binding of a compound to this protein actually inhibit the replication and transcription of the virus and ultimately, stop the virus multiplication. Incorporation of any functional groups to the basic benzylidenechromanones enhance their binding ability. Chloro and bromo substitution amplify the binding affinity. ADME studies of all these compounds indicates they are lipophilic, high gastro intestine absorbable and blood-brain barrier permeable. The outcome reveal that the investigated benzylidenechromanones can be examine in the case of 2019-nCoV as potent inhibitory drug of CoV M pro , for their strong inhibition ability, high reactivity, and effective pharmacological properties.

\section{Introduction}

In this time, the entire world is facing a threat of a new coronavirus, 2019-nCoV. It first appeared in the Wuhan province of China and spread rapidly in the different parts of the world. According to WHO, there is 93090 confirmed cases of 2019-nCoV infection with 2223 new case and 2984 deaths found around the globe, as of 4th March 2020 [1]. Only 9096 patients were recovered and the rate of infection is much higher than that of recovery. At this moment instigation for effective, safe and easy synthesizable therapeutics is in high demand $[2,3]$.

The virus 2019-nCoV, a mutant variety of lineage $B$ betacoronavirus, use angiotensin- converting enzyme 2 (ACE2) of human cell as a receptor during infection like other severe acute respiratory syndrome (SARS)-CoV [4]. Coronavirus has largest viral positive-stranded RNA [5] with protein envelop. The maturation process of (SARS)-CoV is streaming through protein cleavage of polyproteins which influence the replication and transcription of the virus. The CoV main protease (CoV Mpro) is the key enzyme in this event. Inhibition of the protein is an attractive strategy for the coronavirus control. Any kind of mutation of the gene correspond to the CoV Mpro can produce its mutant variety which can partial or complete resistant of these compounds. Development of new anti-CoV Mpro compounds is very essential for combat such rapid mutation able viruses.

In drug discovery, chroman-4-one backbone has privilege due to their suitable pharmacokinetics. Many of them are under clinical trial and hesperetin is one of the member of this family has got clinical approval for cholesterol-lowering medicine [6]. Benzylidene- chromanone are very important but a small class of compounds found Hyacinthaceae and Caesalpinioideae plant [7-9]. Several synthetic and naturally occurring 3-benzylidene-4- chromanones are closely resemble with flavones and they are used as antimutagenic [10], Anti-tumor [11], antioxidant [12] and antiviral [13] activities. It is also found in literature 
that the benzylidenechromanone have the inhibitory properties to different proteins and receptors like monoamine oxidase, [14] a-glucosidase, [15] efflux pump [16] and 5-lipoxygenase (5- LOX) enzyme [17]. This inspire us to use the benzylidenechromanone in the development of molecules against 2019-nCoV.

In this manuscript, we tested various chromanones desigened for the inhibition of the replication and transcription of 2019-nCoV on the basis of different computational studies. The structure of the coronavirus main protease of the mutant variety has been utilised here to designing its inhibitory molecules. The investigation is consist of several phases like modelling of protein structure, pharmacology and pharmacokinetics of 3-benzylidene-4-chromanones, DFT-based study to resolve the structure-activity relations of chromanones with mutant CoV Mpro and molecular docking study of chromanones with CoV Mpro proteins. From best of our knowledge, we may say that it is the first approach to develop new drug molecule for treatment of the 2019-nCoV.

\section{Result And Discussion}

\section{Protein structure}

The outbreaks of virus attack at Wuhan region of China is the case of new type of coronavirus from bat origin, 2019-nCoV [4]. For this reason, we have very little information about its genetic material as well as structures of different proteins. Fortunately, in recent time, structure of CoV Mpro protein of 2019-nCoV has been determined using x-ray crystallography [18]. It is interesting to observe that the amino acid sequence of CoV Mpro protein of 2019-nCoV is highly different from the previously known CoV Mpro. This mutation produce a novel variety of the protein with same activities. The change in the secondary and tertiary structure of the protein is clearly noticeable in the overlying picture of mutant (pink, pdb id: 6lu7) and one of the known protein [19] (cyan; pdb id: 2q6f) is shown below (Figure 1a). The huge change of the mutant protein in almost every region of it, is key cause for the drug resistance. It creates the scope of development of new compounds against 2019-nCoV.

The study has been extended further to identify the extent of mutation of the novel CoV Mpro by alignment of multiple protein sequence (Figure 1b). In this bioinformatics study, more two formerly known CoV Mpro (pdb ids: $2 q 6 \mathrm{~d}$ and $2 \mathrm{~h} 2 \mathrm{z}$ ) included to get more clear idea about the new mutation. Taking $2 q 6 d$ protein as a reference sequence, it was found that the aligning of the length of mutant protein (6lu7) is covered almost $96 \%$ which is also found other two aproteins. The mutant protein exhibited consensus $70 \%$ which is minimum among them. This is the indication of huge mutation (Figure S1).

\section{Choice of organic compounds}

The mutant CoV Mpro contain nucleophilic amino acid residues (His-41, 163, 164 and 172) at the active site which can be utilized as nucleophile donor in Michael reaction (Figure S2). In natural sources, there are a number of heterocyclic moieties but the flavone (1) have a special recognition due to their easy availability and high activities on different health benefit [20]. 3- Benzylidene-4-chromanones (2) has high 
structural resemblance with flavone (Figure 2). In both the cases, there are one a,b-unsaturated $\mathrm{C}=\mathrm{C}$ double bond and one rotatable phenyl ring is present. It can interact with different types of proteins and receptors as a blocking agent like flavones.

In the case 2 , it contain one reactive exo-cyclic a,b-unsaturated $\mathrm{C}=\mathrm{C}$ double bond without conjugation with any oxygen atom. The extended conjugation of ring oxygen with ketone group reduces the reactivity of the C2 (Michael acceptor site) and C4 position of the molecule 1. The presence of exo-cyclic $\mathrm{C}=\mathrm{C}$ double bond at $\mathrm{C} 3$ without previous type of conjugation, allow the compound $\mathbf{2}$ for Michael reaction at $\mathrm{C} 11$ Therefore, there is chance of compound $\mathbf{2}$ as Michel acceptor during interaction with nucleophilic amino acid residue (Cys, Lys, His, Ser and Tyr) of protein molecule. For this reason we prefer to choose compound $\mathbf{2}$ in this study. Compound $\mathbf{2 e}$-i were also be considered to explore the electronic features of $\mathbf{2}$ and it is discussed later.

\section{Molecular Electrostatic Potential (MEP) Analysis}

Molecular electrostatic potential surface give information about the electron rich and electron deficient parts of a molecule which is generate due to the presence of atoms with different electronegativity. This molecular detail helps to predict how much they are potential to take part in chemical reaction and to realize their mechanism of interactions. The high potential energy regions are electron poor (blue) and the low potential parts having correspondingly low potential energy (Red) and the neutral region is green [21].

The MEP of compounds $\mathbf{2 a - i}$ shows that these molecules are capable to form at least two hydrogen bonding (red paches) during protein binding with the help of ketone and chromanone ring oxygen except $\mathbf{2 g}$ and $\mathbf{2 h}$ (Figure 3 ). The electron density of chromanone aromatic ring is quite higher (yellow) due to conjugation of ring hetero-atom which is favourable for $\pi$-staking interaction with electron deficient amino acid residue. It is possible to modulate the electron density at benzylidene ring and $\mathrm{C} 11$ position by adding different functional groups at benzylidene part. Incorporation of oxygen containing functional groups at benzylidene part ( $\mathbf{2} \mathbf{b}, \mathbf{2} \mathbf{e}$ and $\mathbf{2} \mathbf{h}$ ) increases the electron density to the ring (Figure 3 ). The halogen atoms at this part are unable to influences the electronic behaviour of the ring (green for $\mathbf{2 c}, \mathbf{2 d}$ and $\mathbf{2 g}$ ) whereas the atom concentrate electron density around it. Therefore, it is expected that these compound may interact strongly with protein through $\pi$-staking as well as halogen bonding. In the case of compound $\mathbf{2 f}$, the electron rich oxygen containing furan ring can bind strongly. The extended conjugated hydrophobic benzylidene system is $\mathbf{2} \boldsymbol{i}$ and sufficiently electron rich (Figure 3 ). Therefore, small red, yellow and blue patches on large green surface of compounds chosen for these studies are the indication of balance between hydrophilic and hydrophobic part which is essential for good binding to the protein.

For the assessment of bioavailability, absorption, distribution, metabolism and excretion (ADME) properties and pharmacokinetic studies of small molecules are major concern. To judge the ability of synthetic of isolated molecules as a drug and approval for clinical trials, it should fulfil the ADME requirements [22]. Here, ten molecules has been assessed for their bioavailability. 


\section{Lipophilicity}

The standard descriptor for Lipophilicity is the partition coefficient between n-octanol and water (log $\mathrm{Po} / \mathrm{w})$. The partition coefficient is so important for pharmacokinetics drug discovery that SwissADME, a very useful web tool for pharmacokinetic evaluation provided a section for the property [23,24]. Several computational methods for log Po/w estimation have been developed with varying performances on different chemical sets. Normally multiple predictors have been used to opt for either the most precise method for a given chemical series or to know the consensus evaluation. The models should be diverse enough so that the prediction of the consensus log Po/w will be more accurate [25]. SwissADME provides access to five free predictive models in this connection, i.e. XLOGP3, an atomic method with corrective factors and knowledge-based library [26], WLOGP, a purely atomistic method based upon Wildman and Crippen's fragmentation method [27], MLOGP is an archetypal topology tool based on a linear relation with 13 molecular descriptors [28,29] SILICOS-IT, a 27 fragments, and seven topological descriptors hybrid system [30] and iLOGP is the physics-based method that uses free solvation energies of n-octanol and water which was calculated using the Generalized- Born and solvent accessible surface area (GB/SA) model.

Each log Po/w values for all the compounds are following same trends. The values are significantly below in the case of $2 \mathbf{i}$ which may be due to the enhancement of electron density and polarity in benzylidene part. The negligible change in the log Po/w values for the compound $\mathbf{2} \mathbf{a}$ and $\mathbf{2} \mathbf{b}$ indicates that the methoxy group cannot increase polarity of these molecules. The presence of halogens $(\mathrm{Cl}$ and $\mathrm{Br}$ ) boost their lipid solubility (Figure 4 ). In case of $\mathbf{2 c}$ and $\mathbf{2 g}$ molecules, the changes are very high which is manifestation of the decrease in polarity and increase of the lipophilicity of the molecule for sulphur atom replacement. In this study, log Po/w values for designed compounds were found in the range of +2.29 to +4.25 (Figure 4, Table S1). These positive values signifies that all the molecules are highly lipophilic and fulfil the essential criteria for drug molecules.

\section{Water solubility}

Water solubility is an important requirement for any drug molecule intends to administer through the oral or parenteral route as the sufficient quantity of the active pharmaceutical ingredients has to be given in a small volume [31, 32]. SwissADME furnishes three different topological methods for estimating water solubility-Esol model [33], Ali model [34] and SILICOS-IT [35]. The Log S values of our compounds were in the range of -3.19 to -4.85 using ESOL Log S method, -2.9 to -4.41 using Ali Log S method and -4.25 to -6.38 for SILICOS-IT method, which are mentioned in the Table-1 and S2. Considering all the models we can conclude that the most of the compounds are moderately water-soluble and some of them show good solubility as the reference value of Log $S$ for moderate solubility is between -4 to -6 and -2 to -4 for good solubility. This suggests that the molecules may be administered in the body through an oral or parenteral route.

\section{Pharmacokinetics}


ADME studies of these molecules also give place to these molecules in the approved drug molecule section. All these molecules have high gastrointestinal absorption which allow them for oral dosing and passed the most important and decision-making standard of drug discovery. Blood brain barrier (BBB) permeability test is passed by all of the compounds. Therefore, they are qualified a fundamental index of drug distribution. High negative values of skin permeability is also offers their less skin permeation. Noninhibition of CYP1A2, CYP2C19, CYP2C9, CYP2D6 and CYP3A4 enzymes was found for most of the compounds (Table S2 and S3). Hence, the chance of degradation of these compounds inside the cell is slow and available for blocking of CoV Mpro. Bioavailability score of all the compounds is indication of high potential as a drug molecules. Synthesis of this compounds is very easy as stipulated in the synthetic accessibility of the compounds. All these values of above mentioned parameters is in the region found for the successful drug molecule. This is make it very close to drug like molecules.

Table 1: Predicted data of water solubility, pharmacokinetics, drug likeness and medicinal chemistry of the designed compound $2 \mathrm{a}-\mathrm{j}$

\begin{tabular}{|l|c|c|c|c|c|c|c|c|c|c|}
\hline & $\mathbf{2 a}$ & $\mathbf{2 b}$ & $\mathbf{2 c}$ & $\mathbf{2 d}$ & $\mathbf{2 e}$ & $\mathbf{2 f}$ & $\mathbf{2 g}$ & $\mathbf{2 h}$ & $\mathbf{2 i}$ & $\mathbf{2 j}$ \\
\hline ESOL Log S & -3.83 & -3.89 & -4.41 & -4.73 & -3.92 & -3.19 & -4.85 & -4.1 & -4.29 & -3.62 \\
\hline Ali Log S & -3.56 & -3.73 & -4.21 & -4.29 & -3.76 & -2.90 & -5.11 & -4.01 & -4.23 & -4.41 \\
\hline $\begin{array}{l}\text { Silicos-IT } \\
\text { LogSw }\end{array}$ & -5.41 & -5.53 & -6.02 & -6.24 & -5.15 & -4.62 & -6.38 & -5.8 & -5.5 & -4.25 \\
\hline GI absorption & High & High & High & High & High & High & High & High & High & High \\
\hline BBB permeant & Yes & Yes & Yes & Yes & Yes & Yes & Yes & Yes & Yes & No \\
\hline Pgp substrate & No & No & No & No & No & No & No & No & No & Yes \\
\hline log Kp (cm/s) & -5.38 & -5.57 & -5.14 & -5.36 & -5.77 & -5.95 & -4.85 & -5.16 & -5.07 & -6.37 \\
\hline $\begin{array}{l}\text { Bioavailability } \\
\text { Score }\end{array}$ & 0.55 & 0.55 & 0.55 & 0.55 & 0.55 & 0.55 & 0.55 & 0.55 & 0.55 & 0.55 \\
\hline $\begin{array}{l}\text { Synthetic } \\
\text { Accessibility }\end{array}$ & 2.74 & 2.87 & 2.73 & 2.76 & 3.00 & 2.77 & 3.17 & 2.55 & 3.05 & 3.29 \\
\hline
\end{tabular}

\section{Docking Study}

Combination of understanding on bioinformatics and molecular docking are also being applied to forecast possible uses and production by industry [20]. Molecular docking has been used here to predict the inhibitory activity of compound $\mathbf{2 a - j}$ against mutant coronavirus main protease enzyme. In this study, we docked all the nine compounds with the CoV Mpro of novel (pdb id: 6lu7) as well as three previously known coronavirus (pdb ids: $2 q 6 f, 2 q 6 d$ and $2 \mathrm{~h} 2 \mathrm{z}$ ). The crystal structure of mutant CoV Mpro contain a peptide fragment in its active site. The peptide also docked and the docking score is considered as the control. All the designed compounds shows much higher binding affinity toward CoV Mpro proteins with respect to the peptide (Table 2). It is so interesting that the compounds bind strongly with the new CoV Mpro in comparison with previously known proteins (Table 2). The study shows that the compound $\mathbf{2} \mathbf{g}$ perform best as anti- mutant CoV Mpro (Table 2). The more curious fact that the more lipophilic molecule bind more strongly with the proteins. The presence of halogen atoms increases electron density as well 
as hydrophobicity of the molecule which goes in favour of their strong binding. The compound exhibited excellent results in all the bioavailability studies as discussed previous sections.

Table 2: Docking score of designed compounds $2 a-j$ and the peptide crystallised with mutant CoV Mpro

\begin{tabular}{|c|c|c|c|c|}
\hline Compounds & 6lu7 & 2q6f & 2q6d & 2h2z \\
\hline Peptide & -4.47 & - & - & - \\
\hline $\mathbf{2 a}$ & -7.16 & -6.78 & -5.16 & -6.86 \\
\hline $\mathbf{2 b}$ & -7.34 & -6.56 & -5.01 & -6.37 \\
\hline $\mathbf{2 c}$ & -7.58 & -6.92 & -5.56 & -5.23 \\
\hline $\mathbf{2 d}$ & -7.64 & -7.01 & -5.87 & -5.29 \\
\hline $\mathbf{2} \mathbf{d}$ & -7.58 & -6.91 & -5.81 & -6.17 \\
\hline $\mathbf{2 f}$ & -6.53 & -6.23 & -5.53 & -6.09 \\
\hline $\mathbf{2 g}$ & -7.85 & -7.15 & -6.19 & -6.91 \\
\hline $\mathbf{2 h}$ & -7.55 & -6.89 & -5.83 & -6.24 \\
\hline $\mathbf{2} \mathbf{i}$ & -7.23 & -6.25 & -5.12 & -5.87 \\
\hline $\mathbf{2} \mathbf{j}$ & -7.88 & -7.21 & -6.31 & -7.13 \\
\hline
\end{tabular}

All the compounds are docked inside the active site of the each of the CoV Mpro proteins (Figure 5a) by means of the hydrophobic as well as hydrogen bonding interactions (Figure S3-S10). The reddest patch in the electrostatic potential map (Figure 2) was on the ketone oxygen, forms hydrogen bonding with Glu 166 amino acid residue, observed in docking study. Amino acid residue Tyr 56, His 41 and 163 involved in $\pi$-staking interaction with both phenyl ring separately. Lone pair $\pi$-staking between Met 49 and 165 with $\mathrm{Cl}$ containing phenyl ring is also an interesting case. The chlorine is in hydrophobic interaction with Cys 44, Met 49, Pro 52 and Tyr 54 residues. The $\pi-\mathrm{C}-\mathrm{H}$ interaction between His 163 and thiochromanone benzene ring as well as $\mathrm{CH} 2$ hydrogen and His 41 also found (Figure $5 b$ ).

The study provides an opportunity to modify these designed drug like compounds in its next level. There is a possibility of rotation of C-C bond designated by cyan colour in Figure $5 \mathrm{~b}$.

This rotation of bond can bring the ball shaped hydrogen at benzylidene ring closer to the Arg 188 . Hydroxyl group substitution at the position of these hydrogen atoms can involve in hydrogen bonding with the amino acid residue. The ball shaped hydrogen in thiochromanone ring is closer to Phe 140 and carboxyl group of Glu 166. Replacement of this by NH2 groupmay capable for hydrogen bonding and ionic interactions. If these substitution occur, the compound $\mathbf{2} \mathbf{j}$ can come into existence. All the above studies also performed for the $\mathbf{2} \mathbf{j}$ and found that the compound performed like other except BBB permeability test. The MEP of $\mathbf{2} \mathbf{j}$ display that the electron density increase in both the aromatic ring due to electron donation of $\mathrm{OH}$ and $\mathrm{NH} 2$ groups (Figure $5 c$ ) which is favourable for $\pi$-staking interactions. The appearancedark blue regions in this MEP surface is clue for strong hydrogen bonding. The compound $\mathbf{2} \mathbf{j}$ bind slightly more strong way with CoV Mpro protein than that of $\mathbf{2} \mathbf{g}$. The slight increment in docking score is for the compensation of the loss of huge number of interactions by the elimination of $\mathrm{Cl}$ group by the stabilising hydrogen bonging with $\mathrm{OH}$ and amine groups. Inside the active site, the attached groups (2j) mentioned earlier form expected hydrogen bonding interactions (Figure 5d). 


\section{Conclusion}

In conclusion, the chromone derivatives can be easy synthesisable drug molecule against novel coronavirus treatment. They can inhibit the coronavirus main protease enzyme of the new virus efficiently. In this in silico study, these molecules passed all the essential tests required for a good drug. Based upon DFT analysis, ADMET properties and the docking, all the designed compounds are effective to the inhibition against 2019-nCoV. The binding prospective can guide to the evolution of a powerful drug for humans to combat on going coronavirus threat. Therefore, these non-peptide compounds, especially $\mathbf{2} \mathbf{g}$ and $\mathbf{2} \mathbf{j}$, are now subject matter of examine for the in vitro assay to disclose their efficient inhibition power for mutant CoV Mpro.

\section{Methods}

The study focused on the mutant and earlier three CoV Mpro, i.e. 6lu7, 2q6d, 2q6f and $2 \mathrm{~h} 2 \mathrm{z}$, respectively, for in silico finding of having the capacity to develop into inhibitors in the near future from chromanone derivatives.

\section{Protein structure modelling.}

The crystal data of all the protein structures were downloaded from Protein Data Bank (PDB ID: 6lu7, $2 q 6 d, 2 q 6 f$ and $2 \mathrm{~h} 2 \mathrm{z}$ ). The structures used for further studies was prepared by Discovery studio $2017 \mathrm{R} 2$ client. The modelling of protein structure was done on I-TASSER. All the pictures of the protein was made with Discovery studio 2017 R2 client and Samson core software.

\section{Bioinformatics.}

The protein sequences of selected four above mentioned proteins have been obtained from Discovery studio 2017 R2 client. The sequences were aligned using the bioinformatics web server Clustal Omega of European Bioinformatics Institute (EMBL-EBI). The outcome of the alignment protein sequences was analysed in the same web server, m-view and visualised it with the colour coding provided by the server.

\section{Density functional theory analysis}

The compounds 2 a-j were optimized with the help of density functional theory using B3LYP functional at 6-311g level of besis set. Molecular electrostatic potential map around the molecular frame work were calculated at the combined B3LYP and 6-31 g level of theory with the 0.03 iso values. For all of these DFT calculations, Gaussian 09W software with D1 revision has been used at windows platform [36].

\section{ADME study}

ADME and toxicity of the designed compounds were predicted at the SwissADME web server [21]. Using huge database, the server can speculate physicochemical properties, lipophilicity, water solubility, pharmacokinetics, drug likeness and medicinal properties with high precision. 
Energy minimized structure of compounds 2a-j, obtained from DFT optimization and were used for docking with the mentioned four protein structures. The structure of the compounds and proteins were prepared in appropriate format for the studies with the help of MGL Tools. For docking studies, AutoDock 4.2 was employed by following standard procedure as described [37]. In this case, a $40 \times 40 \times 40$ grid box has been used.

\section{Declarations}

\section{AUTHOR CONTRIBUTIONS}

N.S. and U.C.H. designed, evaluated and follow-up the calculations. N.S. and R.M. performed the work associated with bioinformatics to identify mutation in new protein. A.H. and M.M. explains the ADME analysis of compounds. All authors analysed and interpreted the reported data. N.S. and U.C.H. wrote the manuscript with assistance and feedback from all other. All authors checked the theoretical results and approved of the manuscript as the final version.

\section{ETHICAL STATEMENT/CONFLICT OF INTEREST}

There is no conflict of interest to declare.

\section{ACKNOWLEDGEMENTS}

The Department of Chemistry, Jadavpur University is gratefully acknowledged for research facilities. We are grateful to researchers supporting project number (RSP-2019/141), King Saud University, Riyadh, Saudi Arabia and the UGC, New Delhi, for financial support. N.S. grateful to RUSA 2.0, New Delhi for fellowship and A. H. thankful to DST, Governmrnt of India for DST Inspire fellowship.

\section{Reference}

1. World Health Organization. Coronavirus disease (COVID-2019) situation reports https://www.who.int/emergencies/diseases/novel-coronavirus-2019/situation-reports (accessed March 4, 2020)

2. Xia S, Zhu Y, Liu M, Lan Q, Xu W, Wu Y, Ying T, Liu S, Shi Z, Jiang S, Lu (2020) Fusion mechanism of 2019-nCoV and fusion inhibitors targeting HR1 domain in spike protein. Cell Mol Immunol, https://doi.org/10.1038/s41423-020-0374-2

3. Jiang S, Du L, Shi Z (2020) An emerging coronavirus causing pneumonia outbreak in Wuhan, China: calling for developing therapeutic and prophylactic strategies. Emerg. Microbes Infect. 9, 275-277

4. Zhou P, Yang X-L, Wang X-G, Hu B, Zhang L, Zhang W, Si H-R, Zhu Y, Li B, Huang C-L, Chen H-D, Chen J, Luo Y, Guo H, Jiang R-D, Liu M-Q, Chen Y, Shen X-R, Wang X, Zheng X-S, Zhao K, Chen Q-J, Deng F, 
Liu L-L, Yan B, Zhan F-X, Wang Y-Y, Xiao G-F, Shi Z-L (2020) A pneumonia outbreak associated with a new coronavirus of probable bat origin. Nature, https://doi.org/10.1038/s41586-020-2012-7.

5. Ziebuhr J (2005) The coronavirus replicase. Curr. Top. Microbiol. Immunol. 287, 57- 94.

6. Drug Bank, http://www.drugbank.ca/drugs.

7. Lin L-G, Liu Q-Y, Ye Y, (2014) Naturally Occurring Homoisoflavonoids and Their Pharmacological Activities, Planta Med, 80, 1053-1066

8. Yan J, Sun L-R, Zhou Z-Y, Chen Y-C, Zhang W-M, Dai H-F, Tan J-W, (2012) Homoisoflavonoids from the medicinal plant, Portulaca oleracea, Phytochemistry, 80, 37-41.

9. Lin L-G, Xie H, Li H-L, Tong L-J, Tang C-P, Ke C-Q, Liu Q-F, Lin L-P, Geng M-Y, Jiang H, Zhao W-M, Ding $J, Y e$ Y (2008) Naturally Occurring Homoisoflavonoids Function as Potent Protein Tyrosine Kinase Inhibitors by c-Src-Based High- Throughput Screening, J. Med. Chem. 51, 4419-4429.

10. Perjési P, Das U, De Clercq E, Balzarini J, Kawase M, Sakagami H, Stables J P, Lorand T, Rozmer Z, Dimmock J R, (2008) Design, synthesis and antiproliferative activity of some 3-benzylidene-2,3dihydro-1-benzopyran-4-ones which display selective toxicity for malignant cells. Eur. J. Med. Chem., $43,839-845$.

11. Ma, L-Y, Zheng Y-C, Wang S-Q, Wang B, Wang Z-R, Pang L-P, Zhang M, Wang J- W, Ding L, Li J, Wang C, Hu B, Liu Y, Zhang X-D, Wang J-J, Wang Z-J, Zhao W, Liu H-M (2015) Design, synthesis, and structure-activity relationship of novel LSD1 inhibitors based on pyrimidine-thiourea hybrids as potent, orally active antitumor agents. J. Med. Chem. 58, 1705-1716.

12. Foroumadi A, Samzadeh-Kermani A, Emami S, Dehghan G, Sorkhi M, Arabsorkhi F, Heidari M R, Abdollahi M, Shafiee A (2007) Synthesis and antioxidant properties of substituted 3-benzylidene-7alkoxychroman-4-ones, Bioorg. Med. Chem, Lett. 17, 6764-

13. Emamia S, Ghanbarimasir Z (2015) Recent advances of chroman-4-one derivatives: Synthetic approaches and bioactivities, Eur. J. Med Chem, 93, 539-563.

14. Desideri N, Bolasco A, Fioravanti R, Monaco L P, Orallo F, Yáñez M, Ortuso F, Alcaro S (2011) Homoisoflavonoids: natural scaffolds with potent and selective monoamine oxidase-b inhibition properties, J. Med. Chem., 54, 2155-2164.

15. Famuyiwa S O, Ntumy A N, Andrae-Marobela K, Yeboah S O (2013) Afr. J. Bot., 88, 17-22.

16. Roy S K, Kumari N, Gupta S, Pahwa S, Nandanwar H, Jachak S M (2013) 7-Hydroxy- (E)-3phenylmethylene-chroman-4-one analogues as efflux pump inhibitors against Mycobacterium smegmatis $\mathrm{mc}^{2}$ 155, Eur. J. Med. Chem. 66, 499-507.

17. Siddaiah V, Rao C V, Venkateswarlu S, Krishnaraju A V, Subbaraju G V (2006) Bioorg. Med. Chem. 14, 2545-2551.

18. Liu X, Zhang B, Jin Z, Yang H, Rao Z, The crystal structure of COVID-19 main protease in complex with an inhibitor N3, http://www.rcsb.org/structure/6LU7

19. Xue X, Yu H, Yang H, Xue F, Wu Z, Shen W, Li J, Zhou Z, Ding Y, Zhao Q, Zhang X C, Liao M, Bartlam M, Rao Z (2008) Structures of two coronavirus main proteases: implications for substrate binding 
and antiviral drug design, Virology 82, 2515-2527.

20. Panche A N, Diwan A D, Chandra S R (2016) Flavonoids: an overview, J. Nutritional Science, 5, e47, 115

21. Sepay N, Mallik S, Guha C, Mallik A K, (2016) An efficient synthesis of 1,3-dimethyl- 5-(2-phenyl-4Hchromen-4-ylidene)pyrimidine-2,4,6(1H,3H,5H)-triones and investigation of their interactions with $\beta$ lactoglobiulin, RSC Adv, 6, 96016-96024.

22. Daina A, Michielin O, Zoete V (2017) SwissADME: a free web tool to evaluate pharmacokinetics, druglikeness and medicinal chemistry friendliness of small molecules, Scientific Reports, 7, 42717

23. Pliska V, Testa B, van de Waterbeemd H. (1996) In Lipophilicity in Drug Action and Toxicology, WileyVCH Verlag GmbH, pp. 1-6

24. Arnott J A, Planey S L (2012) The influence of lipophilicity in drug discovery and design. Expert Opin. Drug Discov. 7, 863-875.

25. Mannhold R, Poda G I, Ostermann C. (2009) Calculation of molecular lipophilicity: State-of-the-art and comparison of log P methods on more than 96,000 compounds. J. Pharm. Sci., 98, 861-893.

26. Cheng T, Zhao Y, Li X, Lin F, Xu Y, Zhang X, Li Y, Wang R, Lai L (2007) Computation of octanol- water partition coefficients by guiding an additive model with knowledge. J. Chem. Inf. Model., 47, 21402148.

27. Wildman S A, Crippen G M (1999) Prediction of physicochemical parameters by atomic contributions. J. Chem. Inf. Model. 39, 868-873.

28. Moriguchi I, Shuichi H, Liu Q, Nakagome I, Matsushita Y (1992) Simple method of calculating the octanol/water partition coefficient. Chem. Pharm. Bull. 40, 127-130.

29. Moriguchi I, Shuichi H, Nakagome I, Hirano H (1994) Comparison of reliability of log P values for drugs calculated by several methods. Chem. Pharm. Bull. 42, 976-978.

30. http://silicos-it. s3-website-eu-west-1.amazonaws.com/software/filter-it/1.0.2/filter- it.html

31. Ottaviani G, Gosling D J, Patissier C, Rodde S, Zhou L, Faller B, (2010) What is modulating solubility in simulated intestinal fluids? Eur J Pharm Sci. 41, 452-457.

32. Savjani K T, Gajjar A K, Savjani J K, (2010) Drug solubility: importance and enhancement techniques. ISRN Pharm, 2012,

33. Delaney J S (2004) ESOL: Estimating Aqueous Solubility Directly from Molecular Structure. J. Chem. Inf. Model. 44, 1000-1005.

34. Ali J, Camilleri P, Brown M B, Hutt A J, Kirton S B (2012) Revisiting the general solubility equation: in silico prediction of aqueous solubility incorporating the effect of topographical polar surface area. $\mathrm{J}$. Chem. Inf. Model. 52, 420-428.

35. http://silicos-it.be.s3-website-eu-west-1.amazonaws.com/software/filter-it/1.0.2/filter-html

36. Gaussian 09, Revision 01, M. J. Frisch, G. W. Trucks, H. B. Schlegel, G. E. Scuseria, A. Robb, J. R. Cheeseman, G. Scalmani, V. Barone, B. Mennucci, G. A. Petersson, Nakatsuji, M. Caricato, X. Li, H. P. Hratchian, A. F. Izmaylov, J. Bloino, G. Zheng, L. Sonnenberg, M. Hada, M. Ehara, K. Toyota, R. 
Fukuda, J. Hasegawa, M. Ishida, Nakajima, Y. Honda, O. Kitao, H. Nakai, T. Vreven, J. A. Montgomery, Jr., J. E. Peralta, F. Ogliaro, M. Bearpark, J. J. Heyd, E. Brothers, K. N. Kudin, V. N. Staroverov, Kobayashi, J. Normand, K. Raghavachari, A. Rendell, J. C. Burant, S. S. lyengar, J.Tomasi, M. Cossi, N. Rega, J. M. Millam, M. Klene, J. E. Knox, J. B. Cross, V. Bakken, C. Adamo, J. Jaramillo, R. Gomperts, R. E. Stratmann, O. Yazyev, A. J. Austin, R. Cammi, C. Pomelli, J. W. Ochterski, R. L. Martin, K. Morokuma, V. G. Zakrzewski, G. A. Voth, P. Salvador, J. J. Dannenberg, S. Dapprich, A. D. Daniels, Ö. Farkas, J. B. Foresman, J. V. Ortiz, J. Cioslowski, and D. J. Fox, Gaussian, Inc., Wallingford CT, 2009.

37. Sousa; F.; Fernandes, P. A.; Ramos, M. J. Protein-ligand docking: current status and future challenges. Proteins. 2006, 65, 15-26.

\section{Figures}
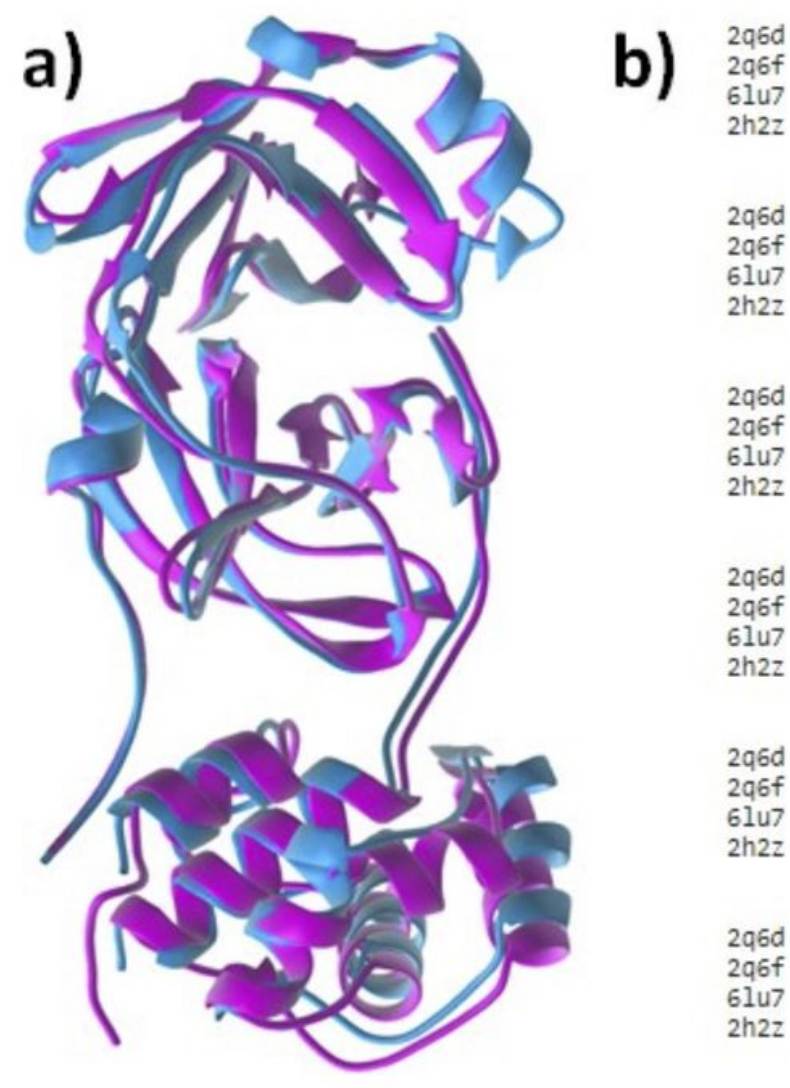

\section{Figure 1}

(a) Overlying picture of mutant (pink) and one of the known protein (cyan) (b) Protein sequence alignment of CoV Mpro (pdb ids: 2q6d, 2q6f, 2h2z, 6lu7) 


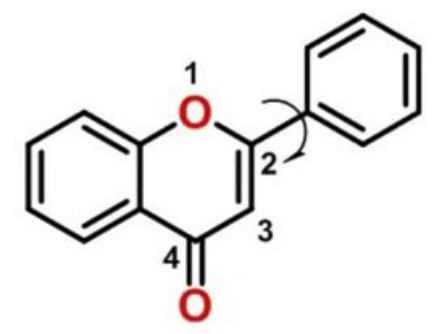

1

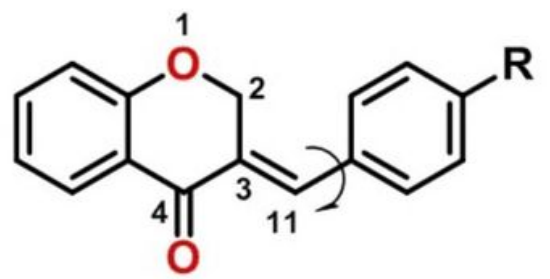

2 2a: $\mathbf{R}=\mathrm{H}$

2b: $R=O M e$

2c: $\mathrm{R}=\mathrm{Cl}$

2d: $\mathbf{R}=\mathrm{Br}$<smiles>O=C1/C(=C/c2ccc3c(c2)OCO3)COc2ccccc21</smiles><smiles>O=C1/C(=C/c2ccco2)COc2ccccc21</smiles>

$2 f$<smiles>O=C1/C(=C/c2ccc(Cl)cc2)CSc2ccccc21</smiles><smiles>COc1ccc(/C=C2\Cc3ccccc3C2=O)cc1</smiles><smiles>O=C1/C(=C/C=C/c2ccccc2)COc2ccccc21</smiles>

\section{Figure 2}

Structural features of flavone and 3-benzylidene-4-chromanones 


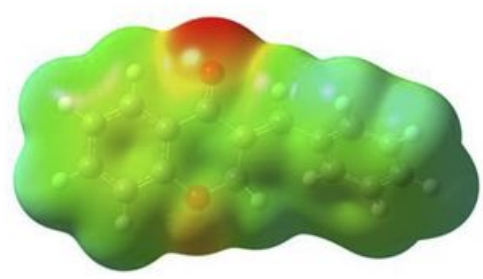

$2 a$

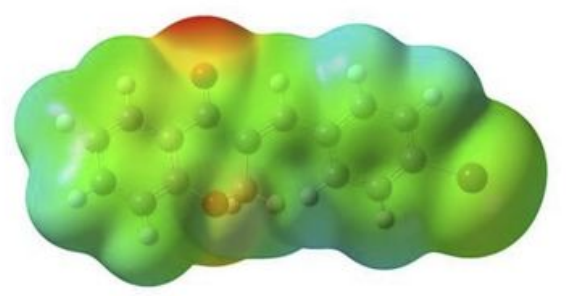

$2 d$

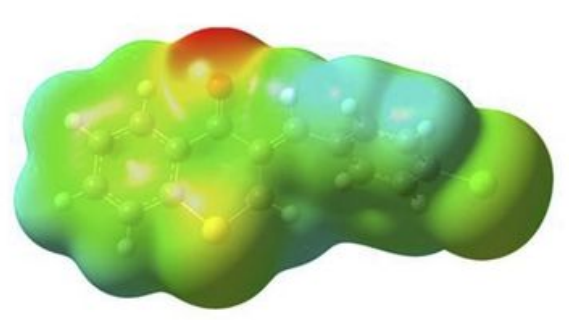

2g

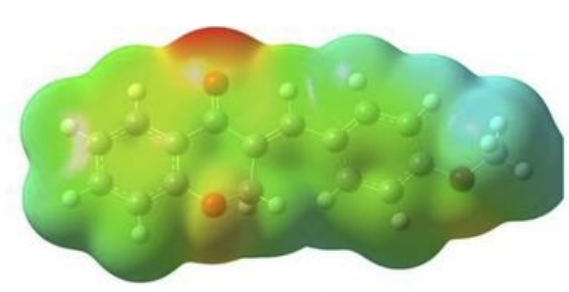

$2 b$

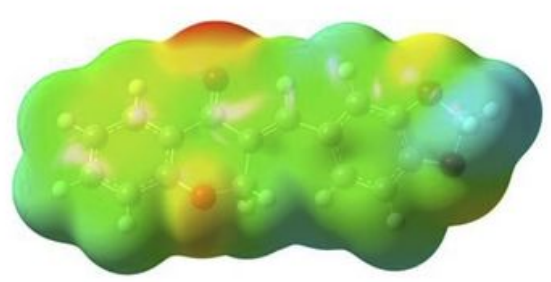

$2 e$

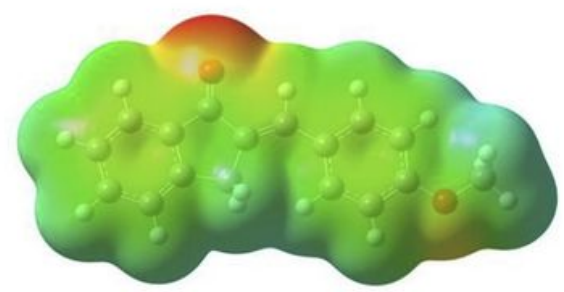

$2 \mathrm{~h}$

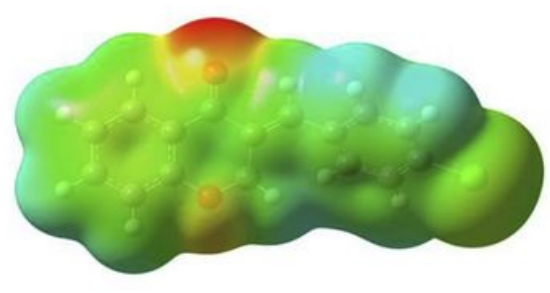

2c

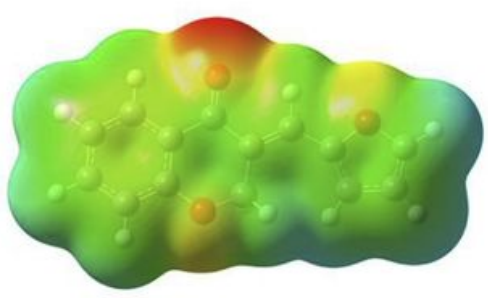

$2 f$

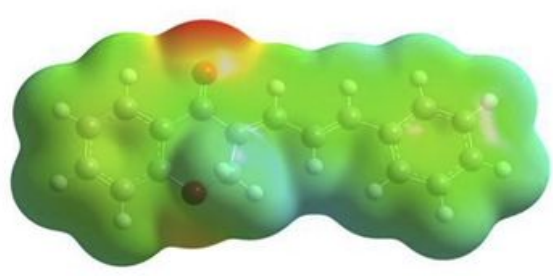

$2 \mathrm{i}$

Figure 3

Molecular electrostatic potential surface of compounds 2a-i. 


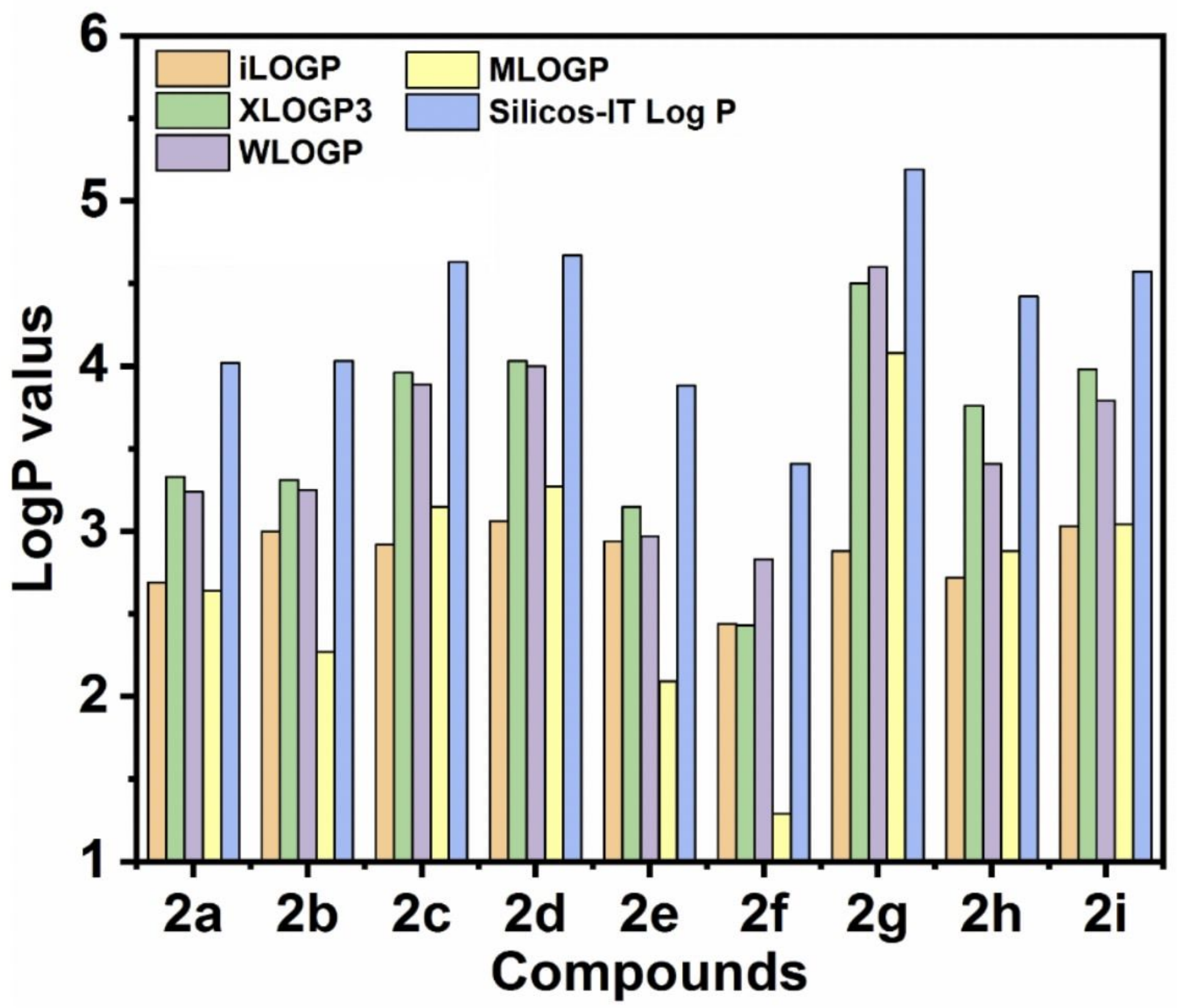

Figure 4

Predicted lipophilicity (logP valuse) of compounds obtained from different calculation models. 


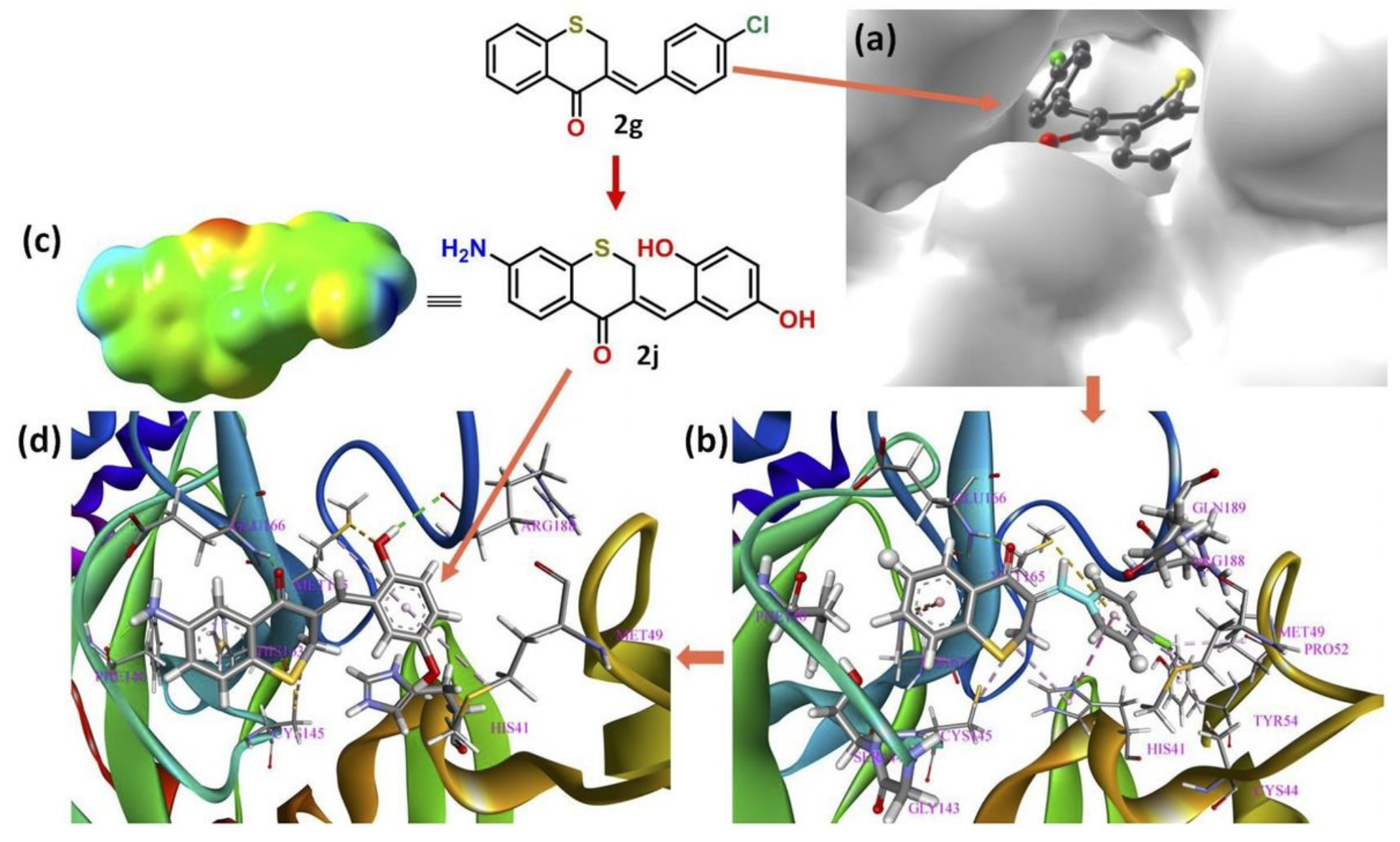

Figure 5

(a) Docking pose (b) binding interactions of $2 \mathrm{~g}$ inside the binding site of mutant Cov Mpro, (c) molecular electrostatic potential map of $2 \mathrm{j}$ and (d) binding interactions of $2 \mathrm{j}$ inside the binding site of mutant Cov Mpro.

\section{Supplementary Files}

This is a list of supplementary files associated with this preprint. Click to download.

- Supportinglnformation.pdf 